\title{
Interview
}

\section{Is there room for a poet in the multi-disciplinary team?}

Selima Hill is one of Britain's renowned poets, and among her many awards was the $£ 5000$ Arvon/ Observer international poetry competition which she won recently with a poem about a psychiatric patient. It was chosen from over 20,000 entries under conditions of strict anonymity. The poem purports to be a patient's diary and is called 'The Notebook'. The disclaimer which preceded it: "This is the notebook of someone who had been an inmate for nearly 20 years. We have typed it out as near as possible as we found it" and the authenticity of its fragmented content had apparently nearly convinced the judges

RP What made you become interested in psychiatry?

SH By visiting a friend in hospital 20 years ago. She was a student at Cambridge with me. I have visited several other people with psychiatric problems since then.

RP Your poems on madness are noted for conveying the experience of being in hospital with an unusually authentic quality; how do you go about achieving that?

SH Well, I suppose I have a fair amount of contact with patients in many different hospitals, like Friern Barnet and the Maudsley.

RP Did the idea for 'The Notebook' come from someone you had visited in hospital?

SH It was suggested by two friends of mine who have had psychiatric problems and whom I have encouraged to write.

RP When 'The Notebook' was recently broadcast on television it was introduced as demonstrating the constant interruptions faced by the psychiatric patient; is that what you see as the main problem faced by patients in hospital?

SH Sometimes. People have often asked me about the poem, as to why its in the form of little snippets one after the other like a journal. You can see that the person is subject to constant interruptions both from the outside, i.e. the hospital routine, but also because of her lack of ability to concentrate and the different persona that she finds herself sitting between. So she has the voice both of the responsible mature adult and of a baby, and a victim, and all of them are different voices-which she can't explain. of the competition that the poem was in fact the product of a patient. 'The Notebook' was recently broadcast on BBC television and another of her poems called 'The Culmination of All Her Secret Longings', which is set in the Maudsley Hospital, has also recently been published.

Rajendra Persaud, a registrar at the Maudsley Hospital, interviewed Selima Hill about her interest in mental illness and her suggestions that poetry can contribute to the understanding and treatment of patients. One of her proposals is that psychiatric hospitals should have 'writers in residence'.

RP It sounds as though you feel the interruptions from the hospital-the ward routine or the doctors or nurses-may get in the way of the patient getting better.

SH I can see that the routine of the ward can be sustaining and protective. I think that is important - with total freedom the person would possibly break down beyond recall; an alternative to a busy hospital's atmosphere might be a more contemplative one, the hospital as retreat as it were. However, it is a difficult responsibility, contemplation by yourself, and I can understand the frequent need for a hospital.

RP You said you encourage patients to write; what is this relationship between writing and mental illness?

SH I think I can see an analogy between being a writer and being a psychiatric patient. Although not all my work is specifically written in the voice of a psychiatric in-patient, I think a writer is in a way a spy and outside of normal society; similarly patients, although they feel authentic within themselves, are outside of everyday life.

RP From your poems it seems your perspective of the patient may be different from that of the hospital professionals.

SH They may be getting a distorted impression of the patient because the hospital routine provides roles for the ill which they can happily regress to. It is sometimes much easier to be passive, like a baby and a victim, than anything else. Sometimes the occupational therapies can make people withdraw even 
more because they don't give the ill sufficient privacy. The patients just put up a screen to keep you away from what is really going on in their minds. There is a line in one of my poems which runs like '... do not console me, you are not my friend...'

RP Would one of the roles of a writer in residence be then to bring a different perspective to patients?

SH Certainly the writer could help the doctor liaise, if even indirectly, with the different kind of sufferer within the patient. In my writing workshops people work from their own strengths and confidences and trust in themselves, which is often different from the role they have accepted.

RP Would the writer in residence be on the ward working with patients like other therapists?

SH Yes, I would be giving myself to the clients. Sometimes I think the phrase "writer in residence' conjures up an image of someone using the hospital as an opportunity to gain material for their own writing. That would not be the idea at all.

RP But wouldn't it be very difficult to avoid the hospital influencing your own writing if you were 'in residence'?

SH No, I don't think so; in the past I haven't written about many things I have been doing. I don't necessarily use the experiences nearest to me. I certainly wouldn't want to exploit the patient's experiences towards some literary end. I think though that a writer in residence writing about hospitals could improve the dialogue between the public and the NHS professionals, just as it can between the healthy and the ill. I also think that writing can improve the atmosphere in hospitals in many ways. There are all sorts of issues here-for instance take Oliver Sach's book The Man who Mistook his Wife for a Hat-some might argue that he is actually abusing his knowledge of the patients; others might feel he has made a major contribution towards understanding those people.

RH Is the role of a writer in residence to encourage patients to write?

$\mathrm{SH}$ Not to write in a literary sense but to do so in order to make contact with the voice that perhaps is silent; maybe comprehending that voice is important in understanding patients and in treating them.

RH But in what way does writing differ from the other art therapies?

SH I think that writing has the drawback of assuming more education than perhaps painting but at the same time it requires less equipment. You can just scribble on the back of an envelope. It also has the virtue of being more private-if you are painting, others can see what you are doing, whereas if you write you can keep it as private as you like. The lack of privacy can have powerful effects. I think privacy leads to freedom. The page offers you a freedom which you can't get in the day-room on the ward.

RP If you see writing as helping to get in touch with a part of patients neither they nor the professionals are in contact with, is that why they are ill in the first place? Is that an explanation of the aetiology of mental illness?

SH Yes, they don't have a centre in themselves. A phrase I often use in my workshops is that a writer isn't a special kind of person, but everyone is a special kind of writer. In other words, everyone can write and it's their own voice they want to find.

RP But most psychiatrists wouldn't conceptualise that as being the cause of mental illnesses in general?

SH I can sympathise with the fact that there are many different explanations. But even if you take biochemical theories of mental illness, peoples' reactions to their illness or biochemical problems are very important. If you have a roomful of people subjected to the same chemical pressures they will react differently according to their inner selves. I certainly wouldn't want to disagree with the professionals or intrude into their territory. Whatever their understandings and treatments I would have thought the way writing can help people find their own way would be useful.

RP Have there been times when you have disagreed with psychiatrists?

SH Sometimes I feel they don't have enough hope in the person contributing to their own healing. I know that sounds naive as I haven't dealt with as many seriously ill people as psychiatrists. But I wouldn't see myself as in conflict with psychiatrists and have never argued about a particular treatment. I don't see that as the role of a writer in residence.

RP What do you feel about the way patients are dealt with in general at the moment in hospitals?

SH I would like to see things less restrictive.

RP Do you mean restrictive in the sense of the use of mental health legislation like in sectionings?

SH I must say that in my experience sections frequently come as a great relief to patients and their families. Often the family or the patient do not want to take certain responsibilities, but if the responsibility is taken over by the hospital and they are no longer liable, this is welcoming to them, although they may not admit it. This is rather like the situation with 
bringing up children where none has to use authority outside of them.

RP You mentioned earlier that you had been to several different hospitals; did you find any differences among them?

SH Their atmospheres do affect me. I was aware of the Maudsley's reputation and I suppose like all labels that label had its effect on me.

RP How does the atmosphere of a hospital affect you?

SH The atmosphere is often deeply disturbing, especially to visitors, and it is interesting that the patients are often not aware of its effect. One of my strong feelings is that the dayrooms of hospitals are dominated by the television. That is often the only stimulation on the wards and this may be very undesirable. We know television has effects on 'normal' people and it may be that patients are even more sensitive to its varying influences.
RP Would your ideas on writing apply to all patients or would it be ambitious for some, like the very psychotic or withdrawn?

SH It is ambitious; the person needs to be able to read, write and concentrate long enough to put things down on paper. All the people I have worked with so far, although suffering from breakdowns, have managed some function in the outside world. So this would be ambitious for those who are very ill, but then again maybe it is important to be ambitious.

RP Are there any hospitals that you know of which are interested in the idea of a writer in residence?

SH Although I have been discussing the idea with you in some detail, I have never met one or been one. At the moment its only fantasy. As far as I know, no British hospital has seriously considered the possibilities it represents.

\title{
Chemical castration and consent to treatment
}

\author{
John R. Hamilton, Honorary Senior Lecturer in Forensic Psychiatry, Institute of \\ Psychiatry, London, SE5
}

A funny thing happened to Mr Kenneth Clarke on his way to the House of Commons in October 1982. It was the last day of debate on the Mental Health (Amendment) Bill and for some peculiar reason the then Minister of Health decided to reject the advice he had just been given by DHSS officials and instead accepted at the last minute an amendment proposed by the Opposition which extended the consent to treatment provisions for psychosurgery and certain other (then undefined) treatments to voluntary patients.

A few days later an attempt was made in the House of Lords by Lord Mottistone (on behalf of the Royal College of Psychiatrists) to reverse this amendment for such 'other treatments' on the grounds that there had been no consultation on the proposal, that only five MPs had been present at the time and that it undermined the basic principle of mental health legislation that voluntary psychiatric patients should have the same rights as other patients to receive treatment without interference from the state. The new proposal meant that a voluntary patient would be denied treatment unless at least six other people had discussed his case - his consultant, a team of three from the Mental Health Act Commission and the others who would have to be consulted in the 'consent and second opinion' procedure. There is no doubt from Hansard ${ }^{1}$ that the argument was won (seven peers and peeresses supported Lord Mottistone and only the Government minister was against) but a successful 3-line Government whip was imposed to safeguard the possibility of the Bill being sent back to the House of Commons and therefore being possibly lost.

The story is taken up five years later by which time the Mental Heath (Hospital, Guardianship and Consent to Treatment) Regulations 1983 had stipulated that consent and a concurring second opinion was required for psychosurgery and the surgical implantation of hormones for the purpose of reducing male sexual drive. Dr Gerald Silverman, a consultant psychiatrist with a particular interest in the treatment of compulsive sex offenders, had such a patient who was not responding to cyproterone acetate (Androcur) and medroxyprogesterone acetate (Depo-provera). Dr Silverman learned of a preparation goserelin 